\title{
Success and Failure for Children Born with Facial Clefts in Africa: A 15-Year Follow-up
}

\author{
Anthony S. de Buys Roessingh • Mirko Dolci • \\ Chantal Zbinden-Trichet • Raymond Bossou • \\ Blaise-Julien Meyrat $\cdot$ Judith Hohlfeld
}

Published online: 27 April 2012

(C) Société Internationale de Chirurgie 2012

\begin{abstract}
Background This study reviews the 15 year program of our Department of Pediatric Surgery for the treatment and follow-up of children born with a cleft in Benin and Togo. Methods We analyzed files of children born in Africa with a cleft. They were referred to us through a nongovernmental organization (NGO) between 1993 and 2008 and assessed in Africa by local pediatricians before and after surgery. Operations were performed by our team.

Results Two hundred files were reviewed: 60 cases of unilateral cleft lip, seven of bilateral cleft lip, 44 of unilateral cleft lip palate (UCLP), 29 of bilateral cleft lip palate (BCLP), 53 of cleft palate (CP), three of bilateral oro-ocular cleft, one of unilateral and two of median clefts (Binder), and one of commissural cleft. Sixty-nine (35\%) of these cases were not operated in Africa: $25(12.5 \%)$ had not shown up, 28 (15\%) were considered unfit for surgery (Down's syndrome, HIV-positive, malnutrition, cardiac malformation), and $16(7.5 \%)$ were transferred to Switzerland. Palatal fistula occurred in $20 \%$ of UCLP, $30 \%$ of BCLP, and $16 \%$ of CP. Evaluation of speech after palate surgery gave less than $50 \%$ of socially acceptable speech.
\end{abstract}

A. S. de Buys Roessingh $(\varangle) \cdot$ C. Zbinden-Trichet

B.-J. Meyrat · J. Hohlfeld

Department of Pediatric Surgery, University Hospital Center of the Canton of Vaud (CHUV), 1011 Lausanne, Switzerland e-mail: anthony.debuys-roessingh@Chuv.ch

M. Dolci

Department of Anesthesiology, University Hospital Center of the Canton of Vaud (CHUV), 1011 Lausanne, Switzerland

R. Bossou

Department of Paediatry, Department of Zou and Collines, Abomey Hospital, Benin, Africa
Conclusions Our partnership with a NGO and a local team makes it possible to treat and subsequently follow children born with a cleft in West Africa. Surgery is performed under good conditions. If aesthetic results are a success, functional results after palate surgery need further improvement to promote integration in school and social life.

Benin is a country of West Africa with a population of six million inhabitants. Twenty percent of the population has access to health care, and $50 \%$ has access to drinking water. The Department of Pediatric Surgery of the University Hospital in Lausanne (CHUV) has been providing medical support to Benin and Togo since 1980 by organizing yearly surgical missions and follow-up of the operated children.

The surgical missions are based on a partnership between (1) the Pediatric Hospital of Sedo-Goho in Abomey, Department of the Zou and Collines Province, Benin; (2) the NGO "Terre des Hommes" (TDH); and (3) the Department of Pediatric Surgery, CHUV, in Lausanne. The Province of Zou and Collines numbers more than 900,000 inhabitants. As pediatric surgeons, we treat malformations of the face, such as clefts, aftermath of burns, malformations of the hand, malformations of the urological tract, such as hypospadias, malformations of the digestive tract, plus miscellaneous cases that require general pediatric surgery.

A facial cleft can be labial, labial-maxillary, unilateral or bilateral labial-maxillary-palatal, or isolated palatal. In developed countries, a multidisciplinary team includes several specialists who will handle the diverse problems of children born with a cleft and follow the child through each developmental stage. Depending on the type of cleft and the age of the child, feeding, speech, ORL, dental, 
orthodontic, aesthetic, and also psychological problems will be taken care of. Palatal cleft are specifically associated with poor speech outcome, which needs to be followed carefully. Cleft treatment starts at the time it is diagnosed and ends when the child is fully grown.

Until 2004, all surgical procedures for cleft repair were performed by the same surgeon, and since then, by a senior fellow under the supervision of the first surgeon. Both surgeons are specialized in cleft repair in Switzerland. They follow the Malek procedure (early closure of the palate by 3 months and anterior hard palate and lip closures by 6 months), adapted according to the age of the children.

In 1993, the Pediatric Hospital of Sedo-Goho, the TDH Foundation, and the CHUV signed a partnership agreement whose goals are to: (1) treat the greatest possible number of children in their own country; (2) transfer difficult cases to Switzerland; (3) transmit medical skills to nursing personnel; and (4) offer postgraduate training to local medical personnel. The purpose of this study was to provide an overview of the organization of the missions after 15 years and the results and follow-up of children operated on for a cleft.

\section{Materials and methods}

\section{Organization of the mission}

The first mission takes place in January and lasts 15 days. In the course of this mission, both consultations and surgery (between 55 and 70 operations) are performed in Benin. The mission team is composed of three to four surgeons, one resident, two anesthesiologists, one nurse, and one speech therapist every other year. At present, the children undergo surgery in the operating rooms of a neighboring hospital for adults. There are two operating rooms: one for the cases of plastic surgery and one for other surgery.

The second mission takes place in October and lasts 1 week. It allows the postoperative follow-up of patients and the examination of new patients who will undergo surgery in the course of a later mission. This mission is organized partly in Benin and partly in Togo. The team on this mission is composed of two surgeons and one resident.

\section{History of the collaboration}

The Department of Pediatric Surgery of the University Hospital in Lausanne (CHUV) has provided medical help to Benin and Togo since 1980. The department works with the TDH Foundation, created in 1962 by Edmond Kaiser (1914-2000). At first, our activity consisted mainly of organizing the transfer to Switzerland of children who needed an operation. Surgery, however, could be performed in Togo, at the Hospital "Saint Jean de Dieu" in Afagnan (Prof. Noël Genton). In 1995, the Pediatric Hospital of Sedo-Goho (Fig. 1) was built in Abomey, Benin, by the TDH Foundation in cooperation with Switzerland and another NGO (Intermont, Spain). There are as yet no surgical facilities in this pediatric center, and these children

Fig. 1 The pediatric hospital in Abomey, Benin. The hospital and the operating room
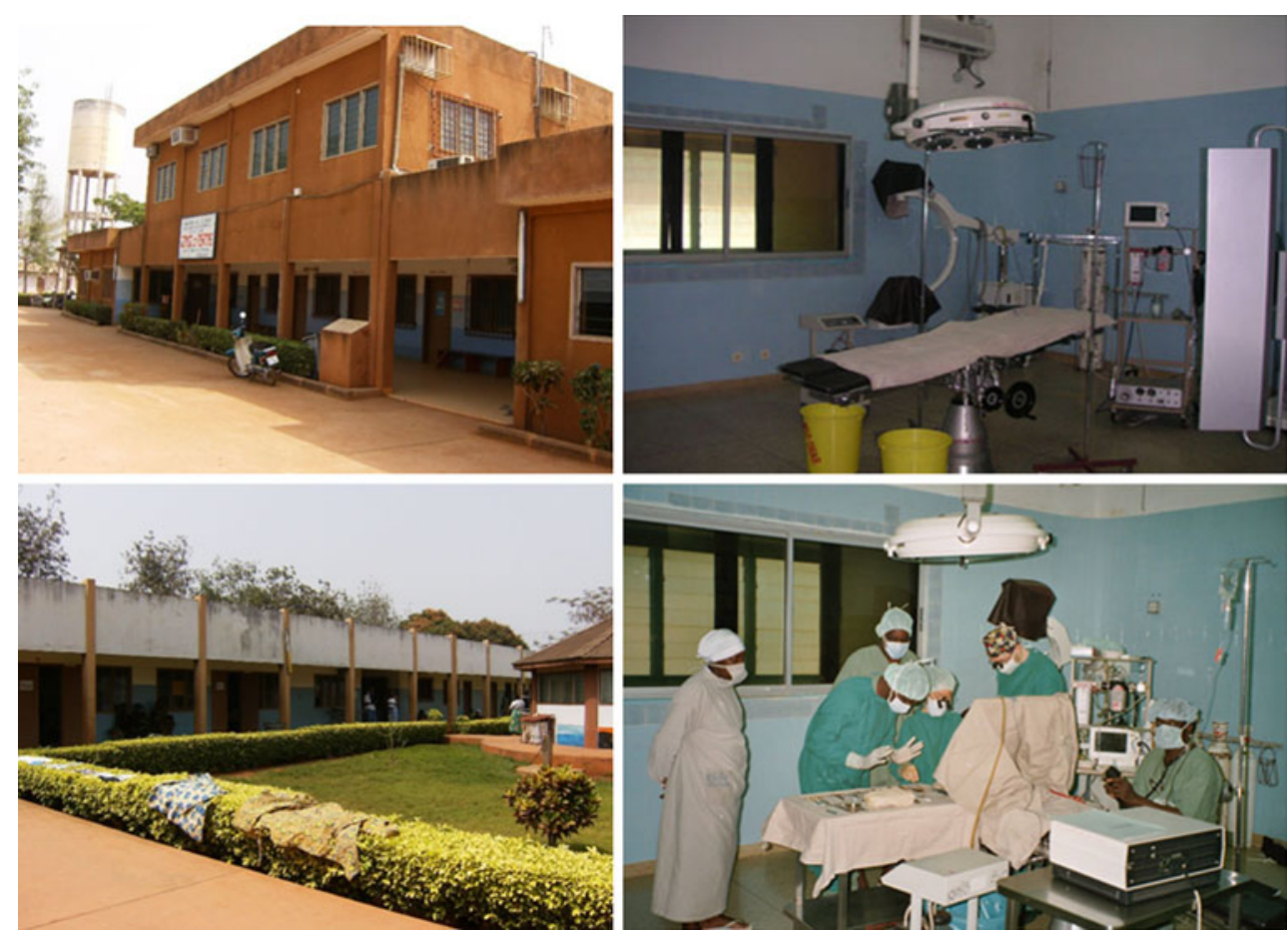
undergo surgery in the operating rooms of a neighboring hospital for adults (Fig. 1). We are at present trying to obtain funding for surgical operating room in the Abomey Pediatric Center.

\section{Role of each partner}

The Pediatric Hospital of Sedo-Goho in Abomey gathers the children and sorts them out according to their pathology, provides the premises for consultations, provides hospital accommodation for the patients, provides laboratory personnel, supports the training of a Beninese surgeon, keeps the medical material sent, sterilizes the material, and provides lunch during the mission. Two pediatricians are in contact with us by e-mail. During the mission, one Beninese anesthesiologist comes on Fridays, Saturdays, and Sundays with two nurses trained in anesthesiology. Two of the local pediatric surgeons spent 1 year in Switzerland at the CHUV (respectively 1989-1990 and 2006-2007) to complete their training.

TDH coordinates contacts with local authorities, organizes local transport for the members of the mission, is responsible for the local transfer of material, assumes a part of the costs of the mission, and provides the local social workers who are responsible for finding the patients in the villages and following them after surgery.

The Department of Pediatric Surgery in Lausanne provides the medical and nursing personnel for the mission, assumes a large part of the costs of the mission, in particular travel and accommodation expenses, procures and ships the material needed for the mission (drapes, masks, gowns, etc.), and procures and brings the drugs that will be needed, some of which are donated by their manufacturers. In addition, it manages the database (File-maker) of our patients. These computerized files include medical history, type of surgery, and follow-up reports and are created for all children, more than 1,550 to this day. The Department of Anesthesiology in Lausanne also provides the medical and nursing personnel for the mission, assumes part of the cost of the mission, in particular travel expenses, and procures the material needed for the mission.

Surgical considerations of cleft repair

Our sequence of operations for children born with UCLP (Fig. 2) is usually soft-palate repair performed at age 2.5 months and anterior hard palate and lip closure at age 5 months, following the Malek procedure. In cases of BCLP, soft-palate repair is performed at age 2.5 months and anterior hard palate and lip closure on one side at age 5 months and on the other side at age 7 months, following the Malek procedure [1]. For children born with $\mathrm{CP}$, closure is performed at 4-6 months. For UCLP and BCLP, a vomer-flap may be used to reconstruct the nasal layer of the velum. All children received antibiotics during 5 days following the operation.

\section{Speech evaluation}

Perceptual speech evaluation is performed by our qualified speech pathologist who is experienced with cleft pathology. The children are interviewed in a quiet playroom in the presence of a parent. Standard upper airway assessment is documented, including the presence or absence of snoring, mouth breathing, apnea, and nasal airway obstruction. Velopharyngeal insufficiency (VPI) or nasal air emission is evaluated according to the Borel-Maisonny classification (Table 1) [2]. Hypernasality, hyponasality, audible nasal emission, voice quality, misarticulations associated with VPI, and intelligibility are assessed. Articulation errors are divided into categories based on their anatomical origin: labial, alveolar, palatine, velar, nasal, pharyngeal, and glottal. The presence of nasal, pharyngeal, or glottal articulation leads to automatic classification as a type 3 articulation score. Postoperative speech evaluation is performed 2 years after the operations. We considered that a phonation of 1-1.5 is a good speech result, leading to an acceptable degree of social integration.
Fig. 2 Example of unilateral cleft lip and palate (UCLP) before and after surgery
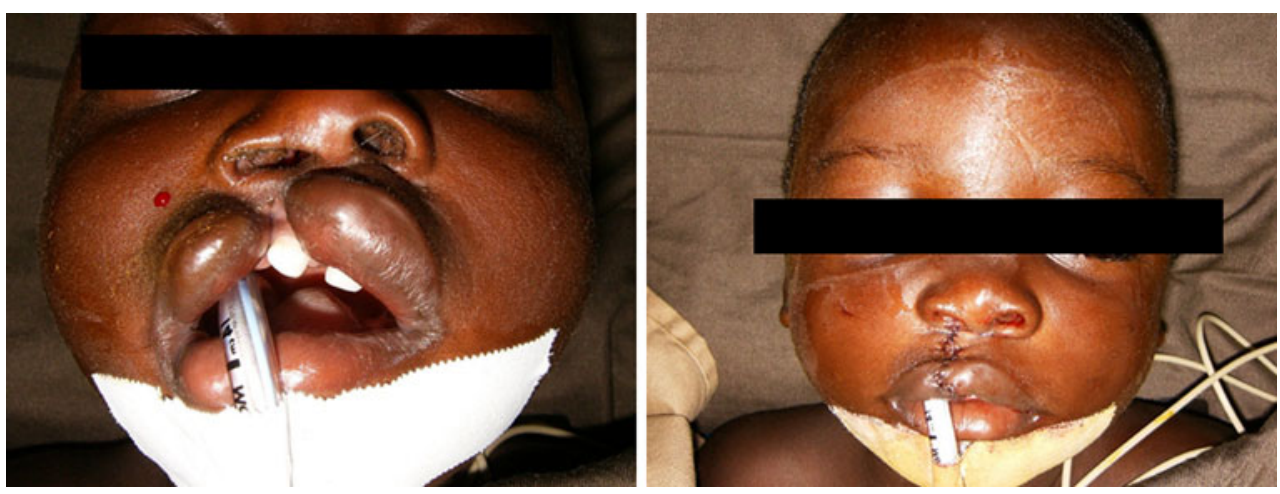
Table 1 Borel-Maisonny classification (phonation)

\begin{tabular}{ll}
\hline Type $\mathrm{O}$ & No phonation \\
Type 1 & Excellent phonation, no nasal air emission \\
Type $1 / 2$ & Good phonation, intermittent nasal air emission, good intelligibility \\
Type 2 & Phonation with continuous nasal emission \\
Type 2b & Phonation with continuous nasal emission but good intelligibility and no social discomfort \\
Type 2M & Phonation with continuous nasal emission, bad intelligibility \\
Type 2/3 & Phonation with continuous nasal emission with compensatory articulation, bad intelligibility \\
Type 3 & Continuous compensatory articulation, no intelligibility \\
\hline
\end{tabular}

\section{Results}

This paper is based on the files of 200 children born in West Africa with a facial cleft who were treated by our team. There were 60 cases of unilateral cleft lip (UCL) and seven of bilateral cleft lip (BCL); 44 cases of unilateral cleft lip palate (UCLP), 29 of bilateral cleft lip palate (BCLP), of which one also presented a hemifacial microsomia; 53 cases of cleft palate (CP), among them five cases of Pierre Robin sequence (PRS, cleft palate, micro/retrognathia, glossoptosis with feeding, and/or respiratory difficulties at birth). There were three cases of bilateral oroocular cleft, one of unilateral, two of median cleft (Binder), and one of commissural cleft (Table 1).

Of the 60 children with UCL ( $29 \%)$, six did not undergo surgery: one was too young, one had a trisoma, one was HIV-positive, and three could no longer be found by the time the mission team arrived. One child was operated on for both an anorectal malformation and a cleft. None of the 54 children operated on suffered postoperative complications (Table 2). The median age for the operation was 25.8 months.

Of the seven children with BCL (4\%), four were not operated: two never showed up, one had a trisoma, and one was HIV-positive. There were no postoperative complications. The median age for the first operation was 14.6 months (Table 2).

Of the 44 children with UCLP ( $22 \%)$, eight were not operated on: five were too young and/or suffered from malnutrition, two never showed up, and one had died for unexplained reasons during the year. Another four were transferred to Switzerland for surgery. Among the 30 children operated in Africa, 20 had one operation and 10 had two operations, the first of which was a veloplasty (Tables 2, 3). Six had a fistula after the operations (20\%). The median age for the operation was 17.2 months. Evaluation of speech problems was realized for 14 children $(35 \%)$, with results summarized in Fig. 3. One child died during the night following the cleft repair; this baby weighed $3.5 \mathrm{~kg}$, was malnourished, and did not withstand the operation.

Of the 29 children with BCLP (15\%), five were too young to be operated, eight never showed up, and six were
Table 2 Types of cleft found in Africa

\begin{tabular}{llll}
\hline Type of cleft & $N(\%)$ & $\begin{array}{l}\text { Operated in } \\
\text { Africa }\end{array}$ & $\begin{array}{l}\text { Operated in } \\
\text { Switzerland }\end{array}$ \\
\hline UCL & $60(29)$ & 54 & - \\
BCL & $7(4)$ & 3 & - \\
UCLP & $44(22)$ & 30 & 4 \\
BCLP & $29(15)$ & 10 & 6 \\
CP & $53(27)$ & 31 & - \\
(Pierre Robin) & $(5)$ & $(3)$ & \\
Bilateral oro-ocular & 3 & & 3 \\
Unilateral oro-ocular & 1 & & 1 \\
Binder & 2 & 2 & - \\
Commissural & 1 & 1 & - \\
Total & 200 & $131(65 \%)$ & \\
\hline
\end{tabular}

Table 3 Follow-up and speech after the operations

\begin{tabular}{llll}
\hline & $\begin{array}{l}\text { UCLP } \\
(n=30)\end{array}$ & $\begin{array}{l}\text { BCLP } \\
(n=10)\end{array}$ & $\begin{array}{l}\text { CP } \\
(n=31)\end{array}$ \\
\hline $\begin{array}{l}\text { Follow-up } \\
\text { (year) }\end{array}$ & 5.6 & 7.6 & 7.6 \\
Age (months) & $\begin{array}{l}17.2 \pm 8 \\
66 \% \text { in one time } \\
(20)\end{array}$ & $\begin{array}{l}15 \pm 9 \\
\text { Two stages } \\
(8)\end{array}$ & $\begin{array}{c}\text { 3 Pierre } \\
\text { Robin }\end{array}$ \\
& $20 \%(6)$ & $30 \%(3)$ & $16 \%(5)$ \\
$\begin{array}{l}\text { Fistula } \\
\text { Speech follow- } \\
\text { up }\end{array}$ & $35 \%(14)$ & $80 \%(8)$ & $45 \%(14)$ \\
$\begin{array}{l}\text { Phonation I or } \\
\text { IIB }\end{array}$ & $9(64 \%)$ & $4(50 \%)$ & $4(28.5 \%)$ \\
\hline
\end{tabular}

transferred to Switzerland for surgery because of other malformations. Five children underwent surgery despite other anomalies (Tables 2, 3). Of the ten children operated on in Africa, eight had two operations and two had three operations. Three had a fistula after the operations (30\%). The median age for the first operation was 15.9 months. Evaluation of speech problems was realized for eight children $(80 \%)$, with results summarized in Fig. 4.

Of the 53 children with cleft palate (27\%), 22 were not operated on in Africa: eight were too young, eight did not show up, five had other anomalies (principally cardiac and 


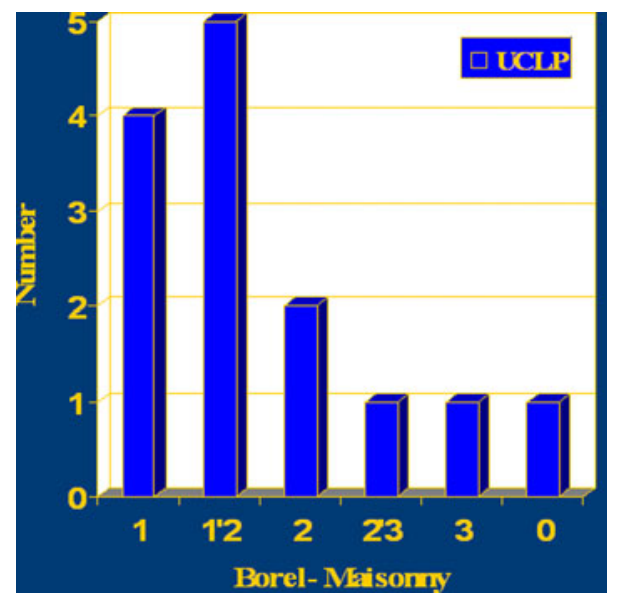

Fig. 3 Phonatory scores for 14 of 30 children born with UCLP (unilateral cleft lip palate) in Africa. Nine children (64\%) had a socially acceptable speech score of 1 and $1 / 2$

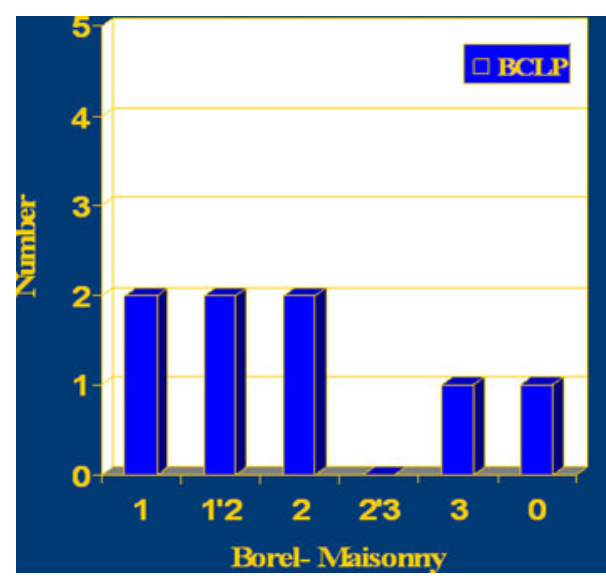

Fig. 4 Phonatory scores for eight of ten children born with BCLP (bilateral cleft lip palate) in Africa. Four children $(50 \%)$ had a socially acceptable speech score of 1 and $1 / 2$

two with trisomy) (13\%) among them two were transferred to Switzerland, and one was HIV-positive. The median age for the operation was 25.6 months (Tables 2, $3)$. Among the 31 children operated on, five had a fistula after the operation $(16 \%)$. Evaluation of speech problems was realized for 14 children (45\%) with results summarized in Fig. 5.

None of the 131 patients operated on in Africa suffered from early postoperative bleeding. None suffered from immediate or late respiratory insufficiency following the anesthesia, and all were correctly looked after by the local nurses in the recovery ward. One child died (UCLP group). Four developed hypoglycemia and took longer to recover. No evident infection (with high fever and pus) occurred postoperatively, even if palatal fistula may be correlated with local infection. Postoperatively, initial signs of malaria were common and children were treated with

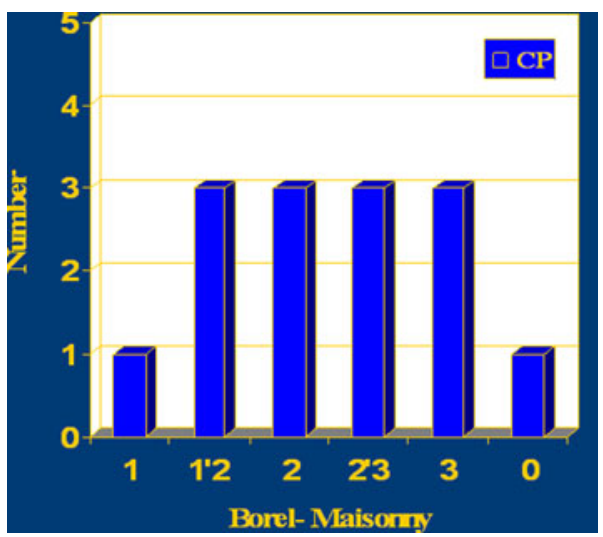

Fig. 5 Phonatory scores for 14 of 31 children born with CP (cleft palate) in Africa. Four children (28.5\%) had a socially acceptable speech score of 1 and $1 / 2$

antimalaria drugs, painkillers, intravenous fluid, and oxygen. As far as late complications are concerned, there were none after lip repair, and any presence of fistula after palatal repair is summarized in Table 3.

\section{Discussion}

Our study shows that foreign surgical missions collaborating with local medical teams to treat children in developing countries, such as Benin and Togo, are not only feasible, but also highly beneficial. However, the functional results of this particular surgery must be evaluated on the basis of the condition of the child as he grows up. The success of cleft repair should not be measured solely on the basis of a good esthetic result, but also, in the long run, on whether it facilitates the social acceptance of the child, his possibility to attend school and receive an education, and his integration in the social activities of the village/town, all of which initially depend to a large extent on the speech quality resulting from the operation; speech is a cornerstone of social integration. Unfortunately, our primary evaluation of this essential aspect of cleft repair shows that functional speech results after surgery are not good enough.

The few resources in developing countries are mostly spent on treating life-threatening conditions, such as malaria, trauma, respiratory infections, or gastrointestinal infections. Yet, in Africa as elsewhere, babies born with a total cleft or a palatal cleft also are at risk of death from starvation [3, 4]. In addition, and if they survive, their integration and social life may be compromised, because, in some regions, malformed children and even their mothers are ostracized [5]. Patients with cleft lips and palates in developing countries depend on these surgical missions, because this difficult plastic surgery procedure is inaccessible to most of these populations [6-8]. 
Children with a cleft palate risk severe speech problems and should be submitted regularly to careful speech and language evaluation [9]. A subjective evaluation of speech problems, especially velopharyngeal insufficiency (VPI), can be done perceptually, by listening to the child's speech. In more highly developed countries, nasometry and videonasopharyngeal endoscopy (VNPE) also are used to assess the nature and degree of the speech problem [10, 11]. In Africa, perceptual speech evaluation alone was done by our speech pathologist experienced in cleft pathology. In French-speaking countries, the reference for the evaluation of VPI or nasal air emission is usually the Borel-Maisonny score (Table 1). Speech therapy can begin at 1 year of age ("guidance") and is designed to strengthen the velopharyngeal muscle complex. Breath control and correct positioning of the tongue and lips can be obtained early by using simple age-appropriate games and making parents aware of the active role they can play in improving their child's speech. Speech therapy must continue for several years to improve the mobility and strength of the velopharyngeal muscle complex [12]. In Africa, all of this is explained to the parents and to the medical team, and since 2002 our speech therapist has organized training sessions every other year, attended also by the parents and their children. The main purpose of these sessions is to teach them that simple daily exercises at an early age are of great importance in speech acquisition.

Our study shows that the prognosis for quality of speech after surgical repair is worse for cleft palate than for total cleft, even bilateral. These results may be explained first by the absence of speech exercises before and after surgery, and second by the lateness of the operation (at 25 months of age) [13]. It is well known that the speech prognosis is better if, whenever possible, palate repair is operated on before age 18 months [8].

Speech results also should be evaluated in the light of the auditory capability of the patients, because children with clefts have a higher probability of presenting secretory otitis media and a consequent transitory hearing loss, which can be a severe problem [14]. No physician in the hospital in Benin checks the ears of children born with a cleft. Part of our mission is to impress on the local team the importance of performing hearing controls on their patients. These controls are quite simple and, when necessary, the ear can easily be drained. This crucial and simple followup is performed routinely in many countries and is even no longer an object of discussion at cleft congresses. This type of control was initiated during our latest mission in Abomey and must be further developed and generally applied. Children with difficult orthodontic problems (functional and esthetic) are for the moment transferred to our hospital in Switzerland. And what about the psychological support for the mother/family?
There are several reasons for the deficient care system in place in many less developed countries: lack of organization, lack of money to procure the good technological equipment needed to provide safe medicine, and lack of skilled physicians and health professionals. This lack of skilled medical personnel, especially in the areas of surgery and anesthesiology, is obvious in West Africa and is one of our main preoccupations. Our goal is to improve the efficacy of medical care by giving further training to local surgeons, providing medical supplies and giving advice on general organization. These goals are possible if local physicians are ready to work toward the same goals and are supported by the local authorities. We trained two local surgeons during 1 year at our hospital in Switzerland. They first had to go through a very difficult phase of adaptation to cultural, social, and behavioral differences, and then, back in their own country, they were confronted by local rules that do not always follow ours or even kept away from surgical practice. Consequently, one of our goals must be to create an independent surgical center with local professionals who can perform these operations on their own and are provided with the necessary equipment to do so. They also will provide basic surgery for children every day.

Working in a developing country contributes to an exchange of interests, and we can learn from them as much as they can learn from us. We recognize our ignorance of their political, cultural, and social customs, and therefore, respect for local people and traditions is the first step in our integration. Medical missions cannot be limited to completing operations and then leaving. The best organizations are those that integrate the domestic sociomedical community by working together with physicians, nurses, and social workers in a personal and collaborative manner. The goal is to share our professional experience with local medical teams, so that they can then organize and pursue their own work. The foreign organization will continue to support them, in particular by donating the medical equipment that will allow these professionals to perform independently.

\section{Conclusions}

Our immediate interactional goals are (1) to pursue our close collaboration with the Pediatric Center of Sedo-Goho in Abomey, and (2) to involve increasingly the Ministry of Health in Benin. Our immediate functional goals are (1) to set up a unit comprising a competent surgeon and a competent local anesthesiology team, (2) to raise funds for the building of a local pediatric surgical unit, (3) to raise funds to ensure the continuity and the autonomy of our surgical missions, and, last but not least, (4) to give the local 
medical personnel the means to become progressively more independent. A well-organized mission is a mission that collaborates with the local team and works under the protection of the political power to ensure the proper treatment and follow-up of its patients.

Parents and local physicians must be made aware that children with clefts risk severe speech problems and should benefit from frequent and specific speech and language evaluations. Their hearing also should be evaluated early and regularly, because they are more likely to have secretory otitis media and the associated transitory hearing loss, which can interfere with language acquisition. The purely esthetic surgical results of our mission have been largely satisfactory. However, this is not enough to ensure the social integration of our patients, particularly in regions where malformed children and their mothers are ostracized. Long-term postsurgical measures are necessary to facilitate the social acceptance of the child and his participation in the activities of the village. This is why our goals are (1) to pursue and ameliorate speech therapy by means of yearly training sessions attended by the parents and their children, (2) to have the local medical staff regularly check the hearing of these children and even perform ear drainage if necessary, (3) to give parents the psychological support they may need already at birth, and (4) to assess the social integration of children several years after the surgery.

Acknowledgment The authors are grateful to Annette Wagnière for reviewing the English text.

Conflict of interest All authors have no financial or relationships with other people or organizations that could inappropriately influence their work. There is no grant support for this research.

Ethical standard Ethical approval given by the Faculty of Medicine of the University of Lausanne, Switzerland.

\section{References}

1. Malek R (2000) Cleft and lip palate. Lesionsm pathophysiology and primary treatment. Martin Dunitz, London

2. Borel-Maisonny S (1975) L'insuffisance vélaire, point de vue de l'orthophoniste. Reeduc Orthophon 13:61-81

3. Mossey PA, Shaw WC, Munger EG et al (2011) Global oral health inequalities: challenges in the prevention and management of orofacial clefts and potential solutions. Adv Dent Res 23:247-258

4. Alkire B, Hughes CD, Nash K et al (2011) Potential economic benefit of cleft lip and palate repair in sub-Saharian Africa. World J Surg 35:1194-1201. doi:10.1007/s00268-011-1055-1

5. Yazdy M, Honeim M, Rasmussen S et al (2007) Priorities for future public health research in orofacial clefts. Cleft Palate Craniofac J 44:251-357

6. Dupuis Ch (2004) Humanitarian missions in the third world: a polite dissent. Plastic Reconstr Surg 113:433-435

7. White EB (2006) Volunteerism and humanitarian efforts in surgery. Curr Probl Surg 43:848-929

8. Saboye J (1999) Plastic surgery training missions in developing countries. A 10-year experience at missions in Mali. Ann Chir Esthet 44:35-40

9. McWilliams BJ, Morris HL, Shelton RJ (1990) Cleft palate speech. BC Decker, Philadelphia

10. Lohmander-Agerskov A, Havstam C, Söderpalm E et al (1993) Assessment of speech in children after repair of isolated cleft palate. Scand J Plast Reconstr Surg Hand Surg 27:307-310

11. Shprintzen RJ (1989) Evaluation of velopharyngeal insufficiency. Otolaryngol Clin North Am 22:519-536

12. de Buys Roessingh AS, Cherpillod J, Trichet C, Hohlfeld J (2006) A comparison of the effect of a cranial-based pharyngeal flap on the speech of children born with a total cleft, an isolated cleft palate or a short palate. J Oral Maxillo Surg 12:1736-1742

13. Agrawal K, Panda K (2011) A modified surgical schedule for primary management of cleft lip and palate in developing countries. Cleft Palate Craniofac J 48:1-8

14. McPherson DI, Jerger J (1971) Impedance audiometry. Arch Otolaryngol 93:338-340 